\title{
Behavioural flexibility during year-round foraging in macaroni penguins
}

\author{
J. A. Green ${ }^{1, *}$, I. L. Boyd ${ }^{2}$, A. J. Woakes ${ }^{1}$, N. L. Warren ${ }^{3}$, P. J. Butler ${ }^{1}$ \\ ${ }^{1}$ School of Biosciences, University of Birmingham, Edgbaston, Birmingham B15 2TT, UK \\ ${ }^{2}$ Sea Mammal Research Unit, Gatty Marine Laboratory, University of St. Andrews, St. Andrews, Fife KY16 8LB, UK \\ ${ }^{3}$ British Antarctic Survey, High Cross, Madingley Road, Cambridge CB3 0ET, UK
}

\begin{abstract}
Penguins are major consumers in the marine environment. However, like many top predators, very little information exists on their foraging behaviour outside the breeding season. We investigated the foraging behaviour of the macaroni penguin Eudyptes chrysolophus continuously for 2 consecutive years, from the end of December 2001. This allowed us to investigate whether foraging behaviour varied between sexes, years or phases of the annual cycle. Male penguins tended to dive deeper and longer than female penguins, but at a lower frequency, probably as a result of their larger body size. There was little variation in foraging behaviour between the 2 years studied, although neither year included a notable period of low Antarctic krill abundance. Diving behaviour varied substantially within years and general linear models were used to investigate this variability. In summary, all penguins tended to dive deeper, longer and more efficiently during their winter migration than during the summer breeding season. The penguins dived predominantly during daylight hours at all times of the year, but appeared to be more constrained by daylight during the short winter days. Several diving variables including dive duration, dive rate and amount of time spent diving were significantly related to day length and these associations were stronger during winter than summer. The macaroni penguin shows flexibility in its foraging behaviour as it adapts to differing constraints and challenges during its annual cycle.
\end{abstract}

KEY WORDS: Behavioural plasticity · Penguin $\cdot$ Southern Ocean · Diving behaviour $\cdot$ Eudyptes chrysolophus Resale or republication not permitted without written consent of the publisher

\section{INTRODUCTION}

Seabirds are important consumers in the marine environment (Croxall 1987). A recent estimate suggests that the annual consumption by the world's seabirds is equivalent to that of all human fisheries combined (Brooke 2004). Understanding where, when, how and on what seabirds feed is essential if we are to understand the dynamics of complex marine systems (Croxall 1987, 1995). In Antarctic and subantarctic waters, penguins constitute a large proportion of the top predator biomass (Croxall 1984, Croxall \& Lishman 1987). The macaroni penguin Eudyptes chrysolophus has the largest population size among penguins (Woehler 1993, Woehler \& Croxall 1997) and may be the single largest consumer among all seabird species
(Brooke 2004). Macaroni penguins breed on subantarctic islands and forage throughout the Southern Ocean (Williams 1995), but our knowledge of the behaviour and ecology of this species is limited. Several studies have examined behaviour during the summer breeding season, when the penguins are constrained by the requirement to return to land regularly (Williams \& Croxall 1991). These include studies of energetics (Davis et al. 1989, Green et al. 2002), foraging location (Barlow \& Croxall 2002b), diving behaviour (Croxall et al. 1993, Green et al. 2003), nest attendance and chick-rearing and diet (Barlow \& Croxall 2002a). However, macaroni penguins spend over half the year, including the entire austral winter, at sea, apparently without returning to land (Williams \& Croxall 1991). During this period, energy expenditure and 
hence food demands are likely to be high (Green et al. 2002), but there is currently no information about the location, foraging habits or diet of macaroni penguins during this period.

This paucity of information on year-round behaviour is not restricted to macaroni penguins. With the exception of some information on location (Weimerskirch \& Wilson 2000, Croxall et al. 2004), no other seabirds, or indeed any other marine predators, have had their foraging behaviour studied continuously throughout their annual (or biannual) cycle. However, several species have been studied at different times of year, or at the same time in years of differing environmental conditions, including king penguins Aptenodytes patagonicus (Charrassin \& Bost 2001) and Antarctic fur seals Arctocephalus gazella (Boyd et al. 2002). These studies frequently identified differences in foraging patterns at different times of the year. The changes are often related to differences in foraging location and therefore the underlying oceanography/topography (Charrassin \& Bost 2001, Boyd et al. 2002) and/or prey species (Kato et al. 2003). This flexibility in behaviour illustrates the importance of studying animals at all stages of their life history, in order to understand how they interact with their environment and how they might respond to environmental change.

Limitations to our understanding of the foraging behaviour of marine predators at sea are primarily a result of the difficulty in gathering information throughout the year. However, miniaturised data loggers or transmitting devices can provide us with information on dive depth (e.g. Lea et al. 2002), location (e.g. Phillips et al. 2004) and feeding behaviour (e.g. Wilson et al. 2002). While the technology underpinning these instruments has improved enormously since they were first deployed over 25 yr ago, technological limitations in memory size and battery longevity are still primarily responsible for our lack of information on the behavioural parameters mentioned above. This has had the immediate effect of restricting deployments of instruments to a few days or weeks. In addition, in order to deploy and/or retrieve instruments, the animals either must return frequently to land or be caught while at sea. Even if these factors did not restrict deployment duration, the size and shape of instruments attached externally to animals can have an adverse effect on their behaviour and survival (Phillips et al. 2003), particularly in the case of streamlined diving animals (e.g. Hull 1997). These effects increase with the duration of deployment and will be of critical importance during winter, when marine food resources are drastically reduced (Foxton 1956, Clarke 1988). These problems are exacerbated in smaller animals and, as a result, even less is known of the role of small seabirds in the marine environment.
In the present study, we used a new design of data logger to record information on foraging behaviour in macaroni penguins continuously for over a year. This instrument has a far greater data storage capacity than other similar loggers and is implanted into the abdominal cavity of the birds to avoid adversely affecting their behaviour (Green et al. 2004). Use of this instrument allows us to determine (1) if macaroni penguins modify their foraging behaviour in response to variability in their environment within years, and (2) at what stage of their annual cycle they exert the greatest predation pressure on their environment. In addition we investigated how foraging behaviour varies between the sexes and between 2 consecutive years commencing with the 2001-02 and 2002-03 breeding season.

\section{MATERIALS AND METHODS}

Study animals. Macaroni penguins were captured and equipped with data loggers (DLs) at the British Antarctic Survey (BAS) base on Bird Island, South Georgia, Antarctica $\left(54^{\circ} \mathrm{S}, 38^{\circ} \mathrm{W}\right)$. All birds used in the experiments were breeding adults from the macaroni penguin colony at Fairy Point on the north side of Bird Island. Although the United Kingdom Animal (Scientific Procedures) Act 1986 does not apply to South Georgia (where this work was conducted), we followed its provisions, especially those set out by the Home Office in the Official Guidance on the operation of the Act. As our benchmark, we followed guidance to researchers using similar methods in the United Kingdom. Our procedures also conformed to the Scientific Committee of Antarctic Research (SCAR) Code of Conduct for Use of Animals for Scientific Purposes in Antarctica.

Deployment of DLs took place during the austral summers of 2001-02 and 2002-03 and retrieval of DLs took place during the austral summers of 2002-03 and 2003-04, respectively. Study birds were identified and captured using the procedures described by Green et al. (2004) and implanted with DLs using previously established techniques (Stephenson et al. 1986, Bevan et al. 1995). Only 1 member of a breeding pair received an implant. Long-term implantation of this device has previously been shown to have no effect on the behaviour, breeding success or survival of this species (Green et al. 2004). In 2001-02, DLs were deployed during the chick-rearing phase in December, January and February ( $\mathrm{n}=39$ ). In 2002-03, DLs were implanted during the incubation phase in November $(\mathrm{n}=19)$, chick-rearing period in January and February $(\mathrm{n}=12)$ and the moult phase in March $(n=12)$. Bird that received implants during the breeding season re- 
turned to foraging duties $54 \pm 4 \mathrm{~h}$ after implantation (range 21 to $122 \mathrm{~h}$ ). DLs were retrieved in the breeding season following implantation. In both seasons, loggers that had failed during the winter migration were removed during the courtship phase, while loggers which had not failed during the winter were removed during the following moult phase. In the 2002-03 breeding season, 34 of 39 penguins with DLs returned after the winter. In the 2003-04 breeding season, 43 of 43 penguins with DLs returned after the winter. In both years, return rates were not significantly different from control groups or previous data for this colony (Green et al. 2004).

Data loggers. The DLs used in the present study were designed by one of the authors (A. J. Woakes) and were the 2 newest versions (Mark 3a, Mark 3b) of an instrument previously used to study diving behaviour of macaroni penguins (Green et al. 2003). Mark 3a instruments were used for all deployments during the 2001-02 season. Mark 3a instruments were also used for 13 of the deployments in the 2002-03 season with Mark 3b being used for the remainder. Both instruments had dimensions of $36 \times 28 \times 11 \mathrm{~mm}$ and weighed $18 \mathrm{~g}$ before and $21 \mathrm{~g}$ after encapsulation in paraffin wax to provide waterproofing and a silicone coating for biocompatibility. Mark 3a DLs had a $32 \mathrm{Mb}$ memory capacity and were programmed to record dive depth every $2 \mathrm{~s}$, and body attitude (upright or prone, using a tilt-switch) every $10 \mathrm{~s}$ for $453 \mathrm{~d}$. Mark 3b DLs had a larger memory capacity (64 Mb) and were programmed to record dive depth every $1 \mathrm{~s}$ and body attitude every $10 \mathrm{~s}$ for $542 \mathrm{~d}$. Mark 3a DLs had a depth resolution of approximately $0.3 \mathrm{~m}$, while a technical problem with the Mark 3b DLs meant that while they had a depth resolution of approximately $0.09 \mathrm{~m}$, they failed to record further depth changes deeper than approximately $25 \mathrm{~m}$ (see Fig. 1). In both years the DLs also recorded heart rate and body temperature, but only the behavioural parameters (dive depth and body attitude) will be covered in this paper. The time that each logger was started, implanted, removed and stopped was carefully noted as GMT. After retrieval, data from all DLs were downloaded onto a computer before being transferred to a UNIX workstation or PC for further analysis.

Data analysis. Data were extracted from 67 data loggers and prepared and analysed using purpose-written computer programs within the SAS statistical package (Version 8.2, SAS Institute). As in previous work (Green et al. 2002, 2003), the recovery period following the implantation period was excluded from the analysis by either (1) ignoring data collected during the period from implantation to the start of the first foraging trip for birds receiving implants during the chickrearing period, or (2) ignoring data collected during the first $52 \mathrm{~h}$ for birds receiving implants during fasting periods (Green et al. 2002). Careful observation of the breeding behaviour of the individual penguins and preliminary analysis of the depth and body-attitude data allowed each day of the deployment for each penguin to be assigned to a phase of the annual cycle and a day since the start of that phase for that bird. These phases were: (1) incubation trip, (2) brood, (3) crèche, (4) pre-moult trip, (5) fail (foraging behaviour during the breeding season following the failure of a breeding attempt), (6) winter (further subdivided to early, middle and late phases [Winter 1, 2 and 3 respectively], each of $70 \mathrm{~d}$ duration). Note that male penguins do not forage during the brood phase and that if penguins fail in their breeding attempt, it is usually during brood or crèche. If this occurred, dives were excluded from further analyses until the pre-moult trip. When data were analysed according to phase, data from individual penguins were included for a particular phase only if the amount of data for that phase from that individual amounted to at least $2 \mathrm{~d}$ worth and at least $25 \%$ of the duration of that phase for that individual. Data for the 2003-04 breeding season were obtained from only 1 penguin and these data were not used in analyses. Variables examined were averaged for each day or each phase for each bird. Therefore in most analyses $n$ is the number of birds (see Table 1). Data were analysed using general linear model (GLM) and linear regression. Day and night periods were calculated using the civil sunset and sunrise times for the latitude and longitude of Bird Island, even though the exact locations of the birds were unknown.

Dive analysis. While evaluating dive records, dives with maximum depths of $<2.4 \mathrm{~m}$ were ignored during analyses since, between the surface and this depth, wave action, recorder noise and the interaction between temperature and pressure degraded depth accuracy making it impossible to accurately characterise dives. In total, 2834420 dives were analysed, and for each dive, maximum depth, dive duration, bottom time and subsequent surface duration were extracted. Following the convention of Tremblay \& Cherel (2000), bottom time was considered to be the time within the dive spent between 75 and $100 \%$ of the maximum dive depth. Vertical velocities were obtained during the descent phase (descent rate calculated from the surface to the beginning of the bottom time) and the ascent phase (ascent rate calculated from the end of the bottom time to the surface). The diving efficiency (DE) was calculated using the equation of Ydenberg \& Clark (1989): diving efficiency = bottom time/(dive duration + post-dive surface duration). The dive:surface ratio ( $\mathrm{D}: \mathrm{S}$ ratio) is given by dive duration:post-dive surface duration. In all analyses, dives were treated as independent events. While accepting that this assump- 
tion may not be strictly correct, it is necessary in order to perform further statistical analyses (Green et al. 2003).

As discussed by Tremblay \& Cherel (2003), a variety of criteria have been used to distinguish foraging and non-foraging (travelling or searching) dives in penguins. In their study of the congeneric rockhopper penguin Eudyptes chryscosome, Tremblay \& Cherel (2003) identified an important and well defined mode at $\leq 5 \mathrm{~m}$ in the distribution of dive depth and chose this as their criterion to define foraging and non-foraging dives. In the present study, and in a previous study of macaroni penguins at Heard Island (Green 1998), a similar mode existed for dives $\leq 10 \mathrm{~m}$ (Fig. 1). Studies of porpoising and travelling dives in similar-sized Adélie penguins Pygoscelis adeliae suggest that dives $>10 \mathrm{~m}$

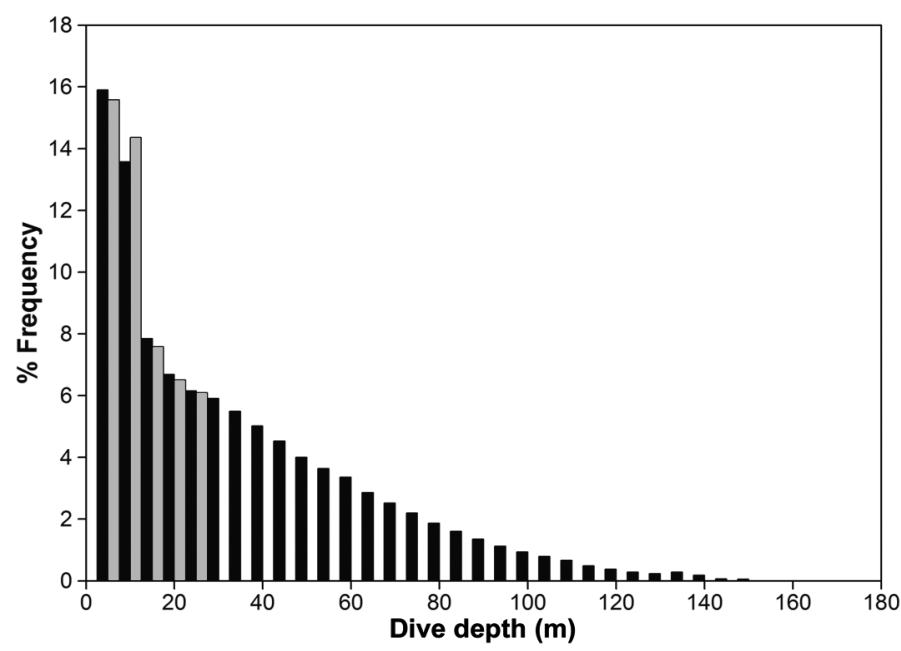

Fig. 1. Eudyptes chrysolophus. Mean frequency distribution of maximum dive depth for 60 macaroni penguins. Penguins equipped with Mark 3a (black bars) and Mark 3b (grey bars) data-loggers (Mark 3b failed to record depth changes deeper than $\sim 25 \mathrm{~m}$ because of technical problems) are almost certainly foraging dives (Yoda et al. 1999, Ropert-Coudert et al. 2001). However, it is difficult to determine precisely whether shallow dives were associated with foraging or travelling activities. In the present study all dives were therefore classified as deep or shallow depending on whether they were $>10 \mathrm{~m}$, and most analyses were performed on deep dives under the assumption that the majority of foraging activity occurs within these dives. Before classification in this way, the distribution of all dive durations for each individual for each phase was bimodal, or unimodal but not normally distributed. After classification, the distributions of both deep and shallow dives were unimodal and normal (evaluated by visual examination of frequency, box, Q-Q and P-P plots), allowing the use of parametric statistics for further analyses.

\section{RESULTS}

\section{Shallow dives}

Data were analysed from 60 data loggers and the duration of the data recorded varied from 11 to $447 \mathrm{~d}$ with an average of $207 \pm 14 \mathrm{~d}$. Variation in the amount of data recorded and start dates resulted in variability in the number of penguins with dive data for each of the different phases of the recording period (Table 1). However, the sample size of both dives and penguins within each phase was sufficient to allow meaningful comparisons to be made. Shallow dives accounted for $29.3 \%$ of all dives recorded, but these dives were only responsible for $13.3 \%$ of all time spent submerged. A general linear model identified differences between individuals in the proportion of shallow dives, but no difference between years, sexes or phases of the breeding season. Shallow dives were not considered in further analyses.

Table 1. Eudyptes chrysolophus. Number of penguins (n) for which dive data were available and number of foraging dives (D1) and non-foraging dives (D2) analysed for each phase of annual cycle. Winter 1 to 3: early, middle and late phases of winter respectively, each of $70 \mathrm{~d}$ duration; numbers in parentheses: number of penguins for which data were obtained using Mark $3 \mathrm{~b}$ dataloggers (see 'Materials and methods'). na: not applicable (male penguins do not go to sea during brood phase)

\begin{tabular}{|c|c|c|c|c|c|c|c|c|c|c|c|c|}
\hline \multirow[t]{2}{*}{ Phase } & \multicolumn{6}{|c|}{ 2001-02 } & \multicolumn{6}{|c|}{ 2002-03 } \\
\hline & $\mathrm{n}$ & $\begin{array}{c}\text { - Female } \\
\text { D1 }\end{array}$ & D2 & $\overline{\mathrm{n}}$ & $\begin{array}{c}\text { - Males } \\
\text { D1 }\end{array}$ & $\overline{\mathrm{D} 2}$ & $\overline{\mathrm{n}}$ & $\begin{array}{c}\text { Females } \\
\text { D1 }\end{array}$ & $\overline{\mathrm{D} 2}$ & $\mathrm{n}$ & $\begin{array}{l}\text { Males - } \\
\text { D1 }\end{array}$ & D2 \\
\hline Incubation trip & 0 & 0 & 0 & 0 & 0 & 0 & $12(8)$ & 40869 & 19259 & $11(9)$ & 50067 & 21532 \\
\hline Brood & 12 & 39156 & 15742 & na & na & & $11(8)$ & 58203 & 26648 & na & na & na \\
\hline Crèche & 13 & 81082 & 32588 & 12 & 45501 & 20965 & $10(7)$ & 98012 & 37776 & $12(11)$ & 95222 & 39773 \\
\hline Pre-moult trip & 14 & 65932 & 36324 & 12 & 43037 & 21539 & $14(11)$ & 70290 & 24096 & $13(12)$ & 62984 & 23321 \\
\hline Winter 1 & 11 & 132360 & 45446 & 9 & 103101 & 30981 & $11(8)$ & 114462 & 65314 & $14(11)$ & 160716 & 71621 \\
\hline Winter 2 & 11 & 113098 & 35560 & 8 & 80171 & 27567 & $8(7)$ & 94192 & 44642 & $10(7)$ & 122896 & 62795 \\
\hline Winter 3 & 7 & 111963 & 41678 & 6 & 91480 & 30581 & $4(3)$ & 57260 & 19121 & $6(3)$ & 71612 & 35885 \\
\hline
\end{tabular}


Table 2. Eudyptes chrysolophus. Analysis of individual component factors of general linear models (GLM) of different diving variables relating to dive $\mathrm{p}<0.001,<0.01$ and $<0.05$

\begin{tabular}{|lrccc|}
\hline Factor & df & $\begin{array}{c}\text { Dive } \\
\text { duration (s) }\end{array}$ & $\begin{array}{c}\text { Surface interval } \\
\text { duration (s) }\end{array}$ & D:S ratio \\
\hline Sex & 1 & $<0.0001^{* * *}$ & $0.0064^{* *}$ & 0.2851 \\
Bird (Sex) & 56 & $<0.0001^{* * *}$ & $<0.0001^{* * *}$ & $<0.0001^{* * *}$ \\
Year & 1 & 0.6663 & 0.2005 & 0.0558 \\
Phase & 6 & $<0.0001^{* * *}$ & $<0.0001^{* * *}$ & $<0.0001^{* * *}$ \\
Sex $\times$ Year $\times$ Phase & 4 & 0.7762 & 0.8477 & 0.3764 \\
Year $\times$ Phase & 5 & 0.5472 & $<0.0001^{* * *}$ & 0.0891 \\
Sex $\times$ Year & 1 & 0.5538 & 0.6225 & 0.1373 \\
Sex $\times$ Phase & 5 & 0.2316 & $0.0026^{* *}$ & 0.5819 \\
$\mathrm{r}^{2}$ & & 0.91 & 0.82 & 0.79 \\
\hline
\end{tabular}
duration. All models were significant at $\mathrm{p}<0.001 .^{* * *},{ }^{* *},{ }^{*}$ : significant at

\section{Variability in foraging behaviour}

Fig. 2 shows the frequency distributions of dive duration throughout the deployments. Clearly, there is substantial variation between phases, and an indication of variability between years and sexes. To investigate this further, general linear model (GLM) and Tukey post-hoc testing were used to investigate how foraging behaviour varied within and between years, sexes and phases; 3 sets of analysis were performed. The first set examined how diving varied in relation to dive duration, allowing comparison
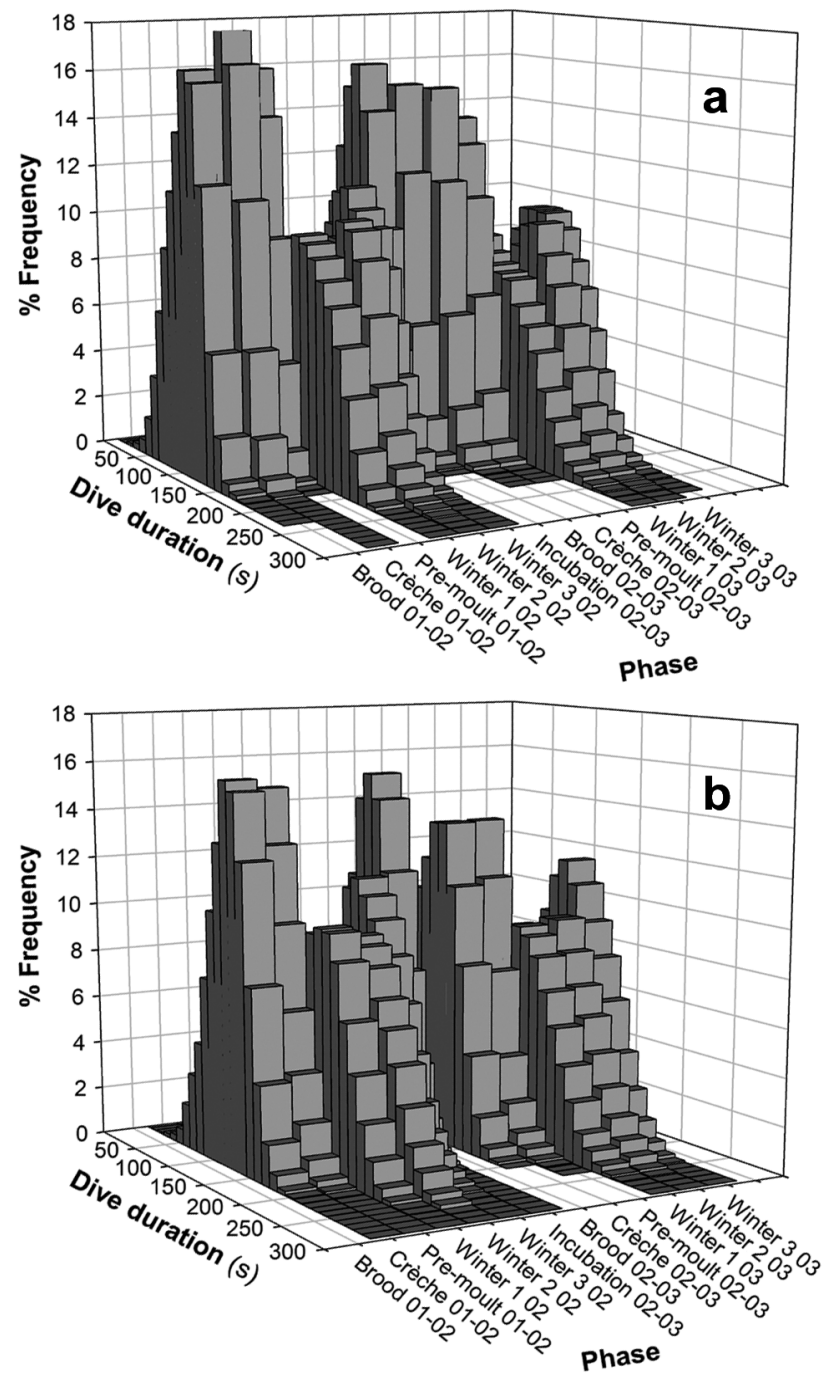

Fig. 2. Eudyptes chrysolophus. Frequency distribution of dive duration during different phases of annual cycle over 2 yr for (a) females and (b) males. Winter 1 to 3: early, middle and late phases of winter respectively, each of $70 \mathrm{~d}$ duration between years as well as sexes and phases. In this analysis, the dependent variables were mean dive duration, mean surface duration and mean D:S ratio. The GLM for each variable was significant ( $p<$ 0.0001); Table 2 describes the results of these analyses in more detail. Fig. 3 shows how interpretation of these data is complex and confounded, but several key features can be identified:

(1) There was significant variation between individual penguins in all diving variables.

(2) There were significant differences between phases of the breeding season in all diving variables. Dive duration was usually longer and surface duration shorter during the winter. The D:S ratio was highest during late winter, lowest during the pre-moult foraging trip and at intermediate levels at other times.

(3) There was no overall significant difference in diving behaviour between the 2 years studied. However, when the phases were compared among years, during the crèche and pre-moult phases, in 2002-03 penguins of both sexes had shorter surface durations than in 2001-02. Dive duration and D:S ratio did not vary between years. Table 3 summarises mean data pooled from both years.

(4) Male penguins had significantly longer dive durations than female penguins and surface durations which were equal or significantly longer. There were no significant differences between the sexes in D:S ratio. Sex-based differences and similarities were consistent between years.

(5) Differences between phases were consistent between the sexes, with the exception of surface duration. In this case, male surface duration was significantly greater than that of females during 2001-02 only.

The second set of analyses examined variables in relation to dive rate and time allocation and also allowed comparison between years as well as sexes and phases. In this analysis the dependent variables were mean 


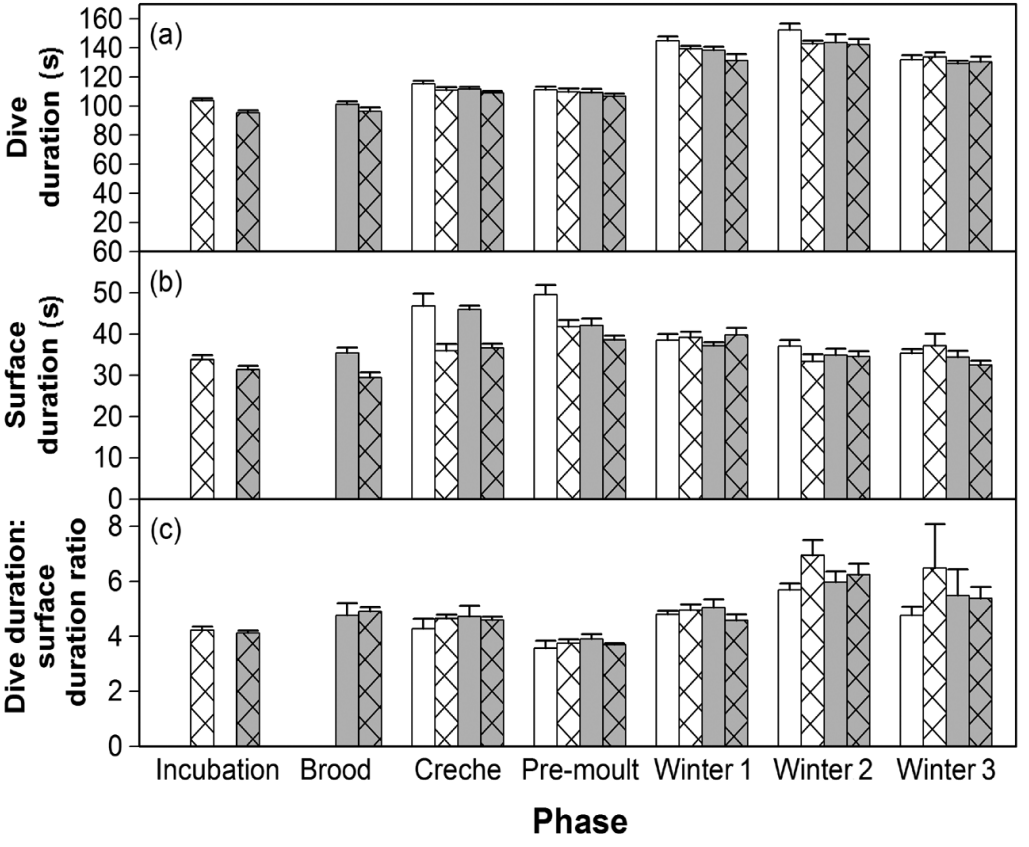

Fig. 3. Eudyptes chrysolophus. Mean (+ SEM) of different diving variables relating to dive duration for males (open bars) and females (filled bars). Unhatched bars: year commencing with 2001-02 breeding season; hatched bars: year commencing with 2002-03 breeding season

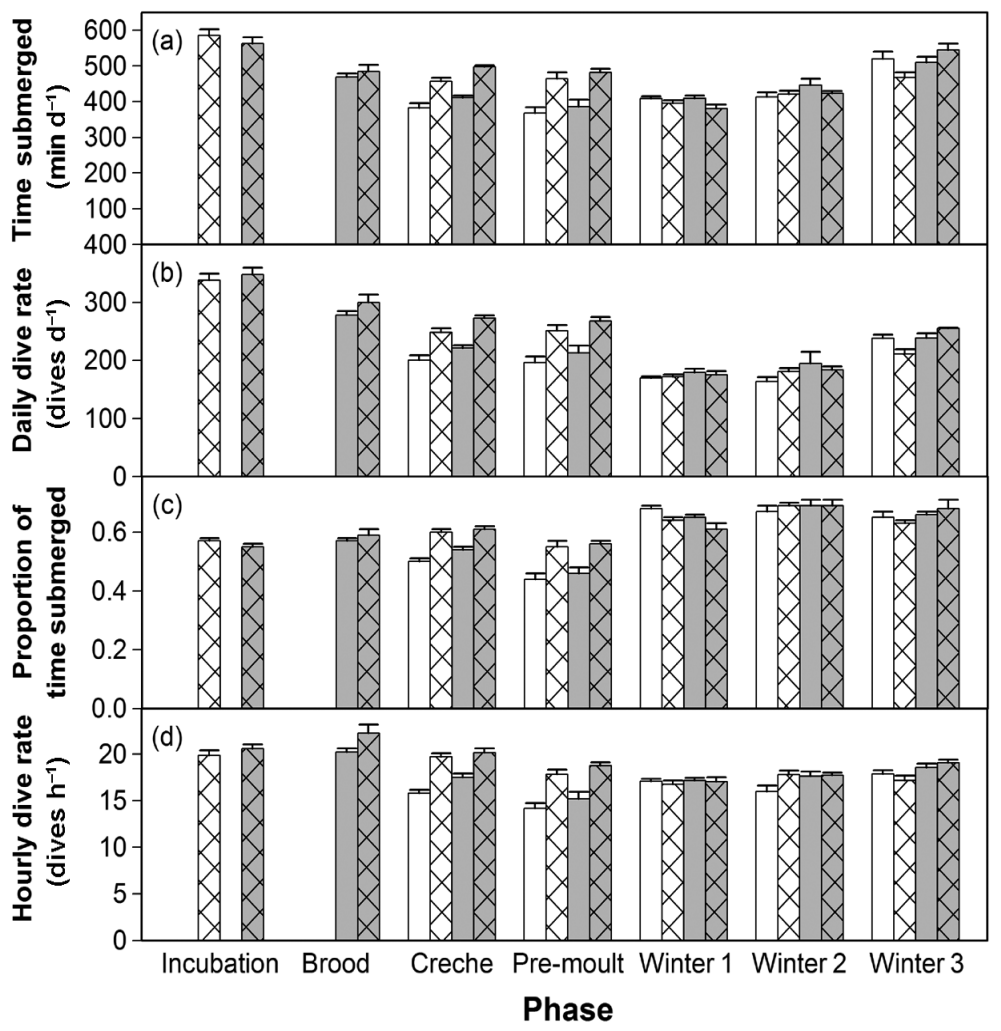

Fig. 4. Eudyptes chrysolophus. Mean (+ SEM) of different diving variables relating to dive rate and time allocation. Shading as in Fig. 3

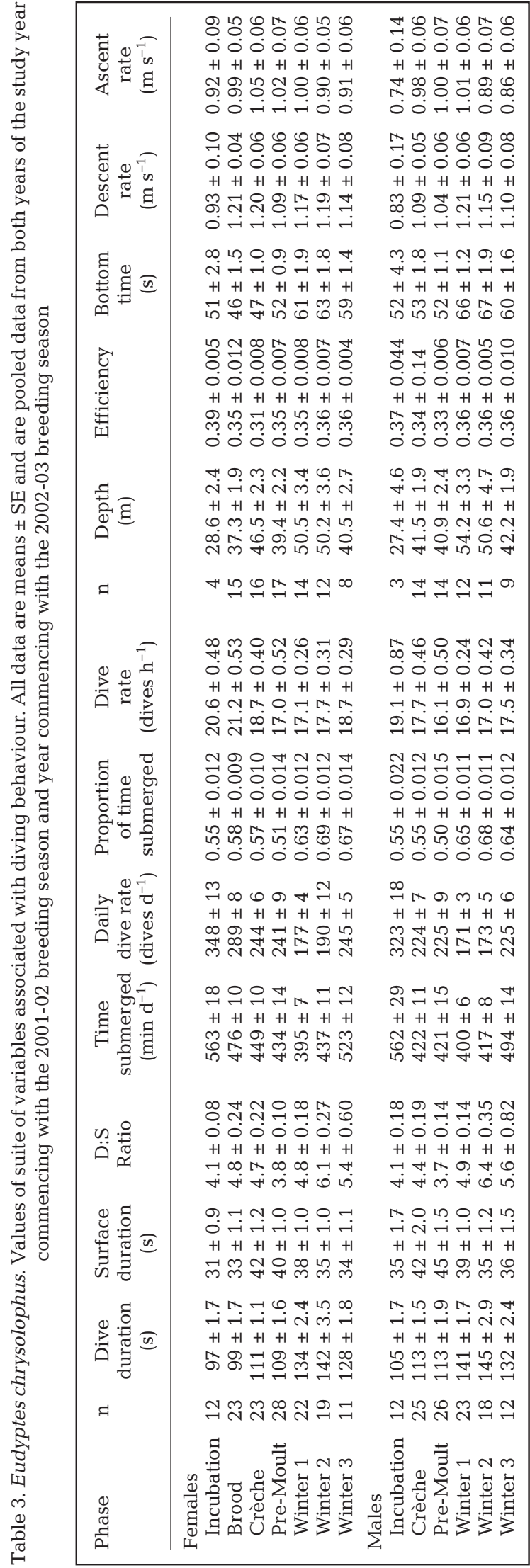


Table 4. Eudyptes chrysolophus. Analysis of individual component factors of general linear models of different diving variables relating to dive rate and time allocation. All models were significant at $\mathrm{p}<0.001 .^{* * *},{ }^{* *},{ }^{*}$ : significant at $\mathrm{p}<0.001,<0.01$ and $<0.05$

\begin{tabular}{|lrcccc|}
\hline Factor & df & $\begin{array}{c}\text { Time } \\
\text { submerged } \\
\left(\text { min d }^{-1}\right)\end{array}$ & $\begin{array}{c}\text { Dive } \\
\text { rate } \\
\left(\text { dives d }^{-1}\right)\end{array}$ & $\begin{array}{c}\text { Proportion } \\
\text { of time } \\
\text { submerged }\end{array}$ & $\begin{array}{c}\text { Dive } \\
\text { rate } \\
\left(\text { dives }^{-1}\right)\end{array}$ \\
\hline Sex & 1 & 0.3760 & $0.0180^{* *}$ & 0.7092 & $0.0004^{* * *}$ \\
Bird (Sex) & 56 & $0.0042^{* *}$ & $<0.0001^{* * *}$ & $0.0222^{*}$ & $0.0003^{* * *}$ \\
Year & 1 & 0.5825 & 0.3850 & 0.6343 & 0.5491 \\
Phase & 6 & $<0.0001^{* * *}$ & $<0.0001^{* * *}$ & $<0.0001^{* * *}$ & $<0.0001^{* * *}$ \\
Sex $\times$ Year $\times$ Phase & 4 & $0.2781^{* * *}$ & 0.3648 & 0.4836 & 0.4775 \\
Year $\times$ Phase & 5 & $<0.0001^{* * *}$ & $<0.0001^{* * *}$ & $<0.0001^{* * *}$ & $<0.0001^{* * *}$ \\
Sex $\times$ Year & 1 & 0.3183 & 0.5900 & 0.5834 & 0.7972 \\
Sex $\times$ Phase & 5 & 0.3404 & 0.9340 & 0.2576 & 0.8521 \\
$\mathrm{r}^{2}$ & & 0.78 & 0.87 & 0.82 & 0.76 \\
\hline
\end{tabular}

each dependent variable was again significant $(p<0.0001)$; Table 4 describes the results of these analyses in more detail and in this case the key features were (Fig. 4):

(1) There was significant variation between individual penguins in all diving variables.

(2) There were significant differences between phases of the breeding season in all diving variables. During the winter, the penguins spent less time submerged per day but a greater proportion of the foraging time was spent submerged. The penguins performed more dives in a day during the summer than during the winter and at a slightly greater rate per hour.

(3) There was no overall significant difference in diving behaviour between the 2 years studied. Table 3 summarises mean data pooled from both years.

(4) Male penguins dived at a significantly slower hourly rate. There were no significant differences between the sexes in mean time submerged or proportion of time submerged. Sex-based differences and similarities were consistent between years.

(5) Differences between phases were consistent between the sexes.

The third set of analyses examined variables in relation to dive depth. As dive-depth data were limited in the second year, analyses were restricted to the first year of deployments (year commencing the 200102 breeding season). In this analysis the dependent variables were mean dive depth, mean bottom time, mean descent rate, mean ascent rate and mean DE. The GLM for each variable was significant ( $p<$ 0.0001) and Table 5 describes the results of these analyses. In this case the key features were (Fig. 5, Table 3):

(1) There was significant variation between individual penguins in all diving variables.

(2) Male penguins dived more deeply than female penguins in all phases except the crèche. Male penguins had a greater bottom time and ascent rate than females, but not during all phases. There was no significant difference overall between the sexes in descent rates and DE.

(3) There were significant differences between phases of the breeding season in dive depth. The penguins dived deeper during the early and mid-winter phases than at other times.

(4) Descent rate varied only slightly between phases; descent rate during the pre-moult trip was less than that at other times. time spent submerged $\left(\min \mathrm{d}^{-1}\right)$, mean dive rate (dives $\left.\mathrm{d}^{-1}\right)$, mean proportion of time spent submerged, and mean hourly dive rate $\left(\right.$ dives $\left.\mathrm{h}^{-1}\right)$. The latter 2 quantities were calculated using the time from the first dive to the last dive for each day for each penguin. The GLM for 
Table 5. Eudyptes chrysolophus. Analysis of individual component factors of general linear models (GLM) of different diving variables. All models were significant at $\mathrm{p}<0.001 .{ }^{* * *},{ }^{* *},{ }^{*}$ : significant at $\mathrm{p}<0.001,<0.01$ and $<0.05$, respectively

\begin{tabular}{|lcccccc|}
\hline Factor & df & Dive depth $(\mathrm{m})$ & Bottom time $(\mathrm{s})$ & Descent rate $\left(\mathrm{m} \mathrm{s}^{-1}\right)$ & Ascent rate $\left(\mathrm{m} \mathrm{s}^{-1}\right)$ & Efficiency \\
\hline Sex & 1 & $0.0485^{*}$ & $<0.0001^{* * *}$ & 0.6442 & $0.0182^{*}$ & 0.4020 \\
Bird (Sex) & 25 & $<0.0001^{* * *}$ & $0.0021^{* *}$ & $<0.0001^{* * *}$ & $<0.0001^{* * *}$ & $0.0001^{* * *}$ \\
Phase & 5 & $<0.0001^{* * *}$ & $<0.0001^{* * *}$ & $<0.0001^{* * *}$ & $<0.0001^{* * *}$ & $<0.0001^{* * *}$ \\
Sex $\times$ Phase & 4 & 0.2547 & $0.0167^{* *}$ & 0.4846 & 0.3814 & $0.0017^{* *}$ \\
$\mathrm{r}^{2}$ & & 0.75 & 0.88 & 0.83 & 0.39 & 0.68 \\
\hline
\end{tabular}

(5) Ascent rate varied significantly but only slightly between phases; ascent rate during the middle of winter was lower than during the crèche phase in female penguins.

(6) The penguins spent longer at the bottom during winter than during the breeding season, but DE varied very little; male penguins dived less efficiently during their pre-moult trip and female penguins dived less efficiently during the crèche phase.

\section{Day-to-day changes in behaviour}

Clearly, there is substantial variation in foraging behaviour between phases of the breeding season. Fig. 6 shows the mean time of the first and last deep dive of the day for each day of the deployments. During the breeding season (November to March inclusive), the penguins tended to forage during the middle of the day with most dives undertaken between sunrise and sunset time calculated for Bird Island. During

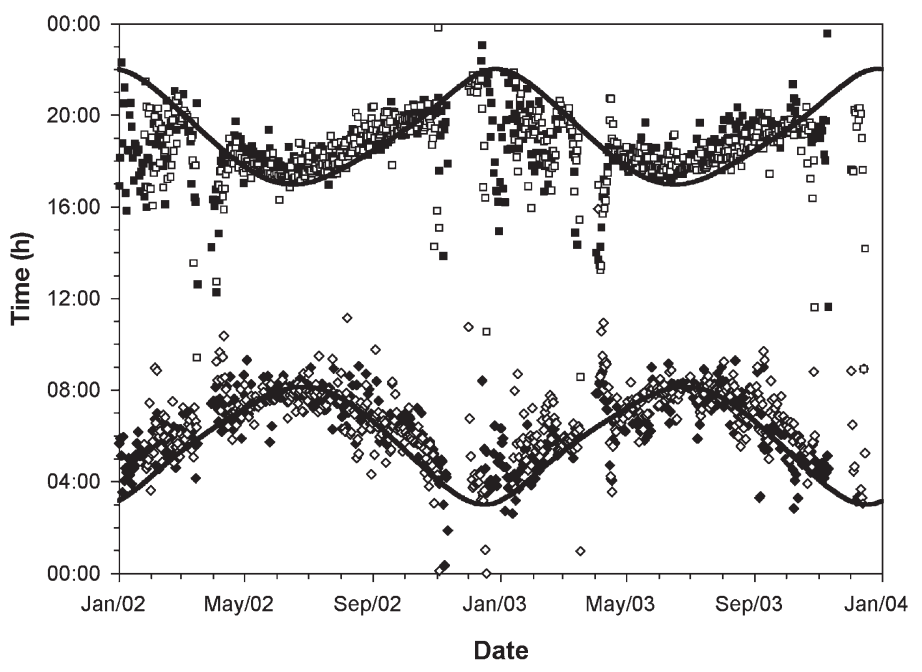

Fig. 6. Eudyptes chrysolophus. Mean start time $(\diamond, \bullet)$ and finish time $(\square, \square)$ of diving activity for males (open symbols) and females (filled symbols) for each day of entire deployment period. Error bars omitted for clarity. Upper and lower lines: sunset and sunrise times respectively, calculated for latitude and longitude of Bird Island $\left(54^{\circ} \mathrm{S}, 38^{\circ} \mathrm{W}\right)$ the winter migration, sunset and sunrise times at the penguins' respective positions are unknown, as they are not constrained to return to Bird Island; yet most foraging took place during the daylight hours calculated for Bird Island. Indeed the mean time of the first and last deep dive appeared to be closer to sunset and sunrise times during the winter than during the summer. Fig. 6 also shows the temporal variation in foraging behaviour between males and females during the breeding season. For example, male penguins do not go to sea during the brood phase in early January and the moult of all penguins is sufficiently synchronous such that no penguins are at sea in late March and early April.

Fig. 6 suggests that the penguins were limited to diving only during daylight hours. Linear regression was used to determine which, if any, diving variables might be related to and therefore potentially constrained by day length. The variables used were mean daily dive duration, mean daily surface duration, mean daily time submerged $\left(\mathrm{d}^{-1}\right)$, mean daily dive rate $\left(\mathrm{d}^{-1}\right)$, mean daily $\mathrm{D}: \mathrm{S}$ ratio, mean daily total time spent diving $\left(\mathrm{d}^{-1}\right)$ and mean daily dive rate in available daylight (number of dives divided by day length from sunrise to sunset). Analyses were run separately for the summer (incubation, brood, crèche and pre-moult trip pooled) and winter (Winter 1, Winter 2 and Winter 3 pooled) periods. Table 6 shows the results of the regressions. Again the results are complex, but the following features can be identified:

(1) Mean dive duration decreased with increasing day length. This association was stronger during winter than summer but in both cases the variability was high.

(2) Mean surface duration decreased with increasing day length during the summer but not during the winter.

(3) Mean number of dives per day, time spent submerged and total time spent diving were related closely to day length during the winter. In the summer these associations were far weaker or not significant.

(4) The D:S ratio increased with increasing day length in the summer months. During the winter, D:S ratio 


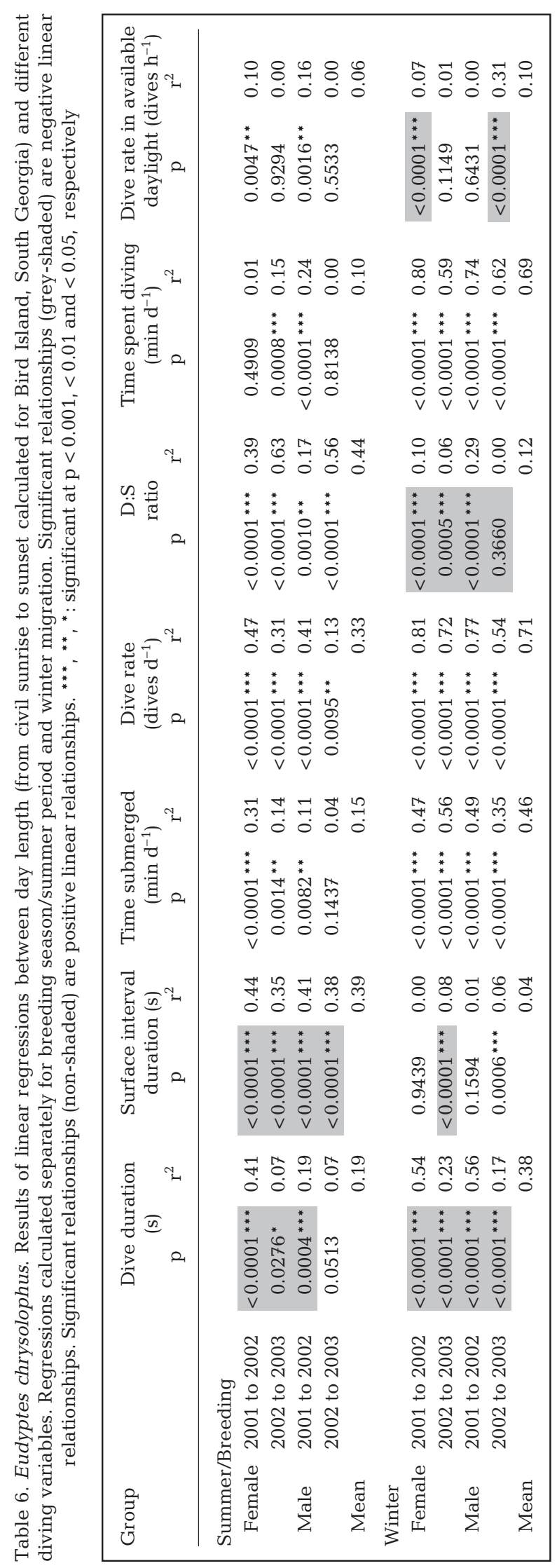

decreased with increasing day length, but these relationships were not as strong.

(5) Dive rate in available daylight showed only a weak association with day length in both summer and winter.

(6) There were no apparent differences between years and sexes in the effect of day length on diving behaviour.

In an effort to demonstrate the variation in foraging effort by the population, Fig. 7 combines data from both years and shows mean time spent submerged $\mathrm{d}^{-1}$, per breeding pair of penguins, for a complete year. Mean time submerged is weighted by multiplying the mean time submerged by the proportion of penguins foraging on that day. This quantity was calculated for both male and female penguins and the resulting totals summed in order to give an index of the foraging effort of a breeding pair of penguins.

\section{DISCUSSION}

To assess the role of predators in the marine environment it is essential to gather data on foraging behaviour at every stage of their life history. The present study illustrates substantial variability in foraging behaviour in macaroni penguins at a variety of scales.

\section{Seasonal variability in foraging behaviour}

Macaroni penguins breeding at South Georgia experience different ecological pressures at different stages of their annual cycle. During the summer, 2 broad types of foraging trips can be identified. During the brood and crèche phases, the penguins engage in short foraging trips to provision their chicks. These trips can last for several days, but $87 \%$ are less than $48 \mathrm{~h}$ in duration with a median of 13 to $14 \mathrm{~h}$ (Barlow \& Croxall 2002a). This restricts the foraging trips to locations relatively close to South Georgia. At this time of year, foraging locations are remarkably similar between individuals, especially during the brood phase, with a mean range of only $62 \mathrm{~km}$ (Barlow \& Croxall 2002b). During incubation and pre-moult, the penguins engage in single long trips of 11 to $14 \mathrm{~d}$ (Williams \& Croxall 1991). During incubation there is more individual variation in location and the mean range of foraging trips is $376 \mathrm{~km}$ for females and $572 \mathrm{~km}$ for males (Barlow \& Croxall 2002b). Despite the difference in nature of the types of foraging trips, diving during the summer was relatively consistent between the different phases.

The foraging location of macaroni penguins during winter is currently unknown, but penguins have yet to be observed ashore. In the present study, body- 


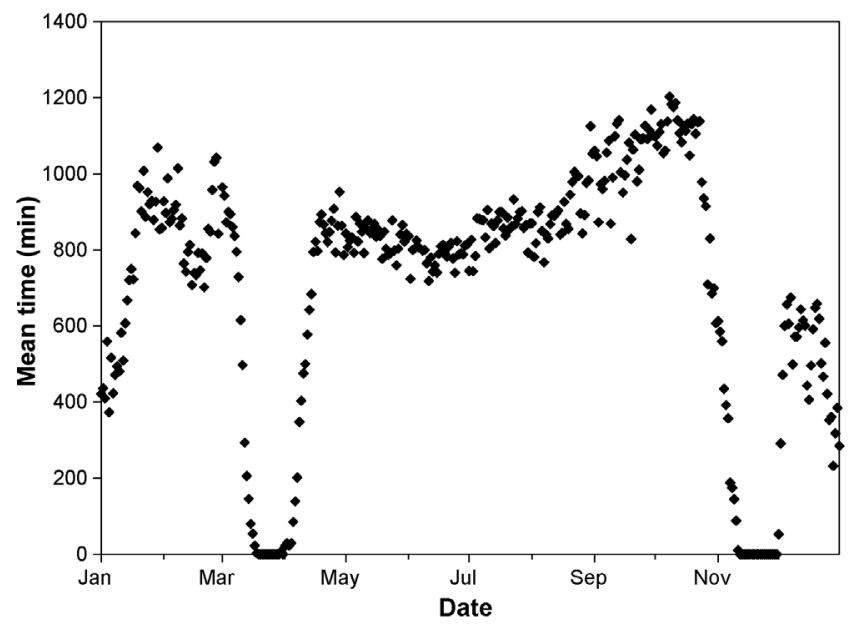

Fig. 7. Eudyptes chrysolophus. Foraging effort for a complete year (combined data for both years, i.e. year commencing with 2001-02 breeding season and year commencing with 2002-03 breeding season) expressed as mean time spent submerged $\mathrm{d}^{-1}$, breeding pair ${ }^{-1}$, weighted by proportion of penguins engaged in foraging on that day

attitude and diving data indicated that none of the penguins came ashore during the winter and it seems reasonable to assume that they spend the entire winter period $(200+d)$ at sea. Foraging behaviour during the winter was quite different from foraging behaviour during the summer. These differences fell into 2 categories relating to (1) differences in the characteristics of individual dives, and (2) differences in the frequency and timing of dives.

\section{Seasonal variability in diving characteristics}

During the winter, the individual dives were longer, to greater depths and had a longer bottom time. The penguins therefore used a deeper part of the water column during the winter, suggesting either a change in location of the prey (Godlewska 1996) or even a change in prey type. These differences were not consistent within the winter, even though differences when compared to the summer remained. This suggests that the penguins may change location during the winter period, or their prey or the location of their prey may vary again (Godlewska 1996). Penguins commonly show a range of responses to changes in prey type and location. For example, in response to variability in diet, location, year, season and conditions of sea-ice, Adélie penguins change not only their diving behaviour, but also the magnitude of this change (Rodary et al. 2000, Ropert-Coudert et al. 2002, Kato et al. 2003). Macaroni penguins at Bird Island have shown themselves to be flexible in their choice of diet. From 1977 to 1996 macaroni penguins fed almost exclusively (mean $96 \%$, range 85 to $100 \%$ ) on Antarctic krill Euphausia superba during the breeding season (Croxall et al. 1997). However, more recent work has shown that macaroni penguins now feed on a variety of different prey, with krill only making up an average of $55 \%$ of the diet during the period from 1996 to 2000 (Barlow et al. 2002). At Marion Island, macaroni penguins also feed predominantly on crustaceans, but the proportion of fish and squid in their diet increases during the breeding season as they are thought to forage further from their breeding sites (Brown \& Klages 1987). Macaroni penguins at Heard Island have a greater proportion of fish in their diet and this proportion also increases as the breeding season progresses (Green 1998). This difference in diet is reflected in a difference in the shape of dives between South Georgia and Heard Island (Green 1998). The diet of the congeneric royal penguin Eudyptes schlegeli remained constant from the incubation trip to the brood and crèche phases in a 3 yr study at Macquarie Island (Hull 1999), despite the penguins also engaging in different length trips and foraging in different locations during these phases (Hull et al. 1997). In contrast to the present study, royal penguins showed no change in diving depth and duration between incubation and chickrearing (Hull 2000), although they did show consistency between years. However, royal penguins forage in deep water (>2000 m) during all summer phases (Hull et al. 1997), while macaroni penguins forage in shallower waters during chick-rearing (Barlow \& Croxall 2002b). Royal penguins did show variation between the phases in time allocation during the dive, presumably in response to differences in location of prey between the foraging areas or the demands of their chicks during the brood and crèche phases (Hull 2000).

Such plasticity in behaviour has also been shown in the con-generic rockhopper penguin (Tremblay \& Cherel 2003), and diving animals commonly alter their foraging behaviour in response to seasonal differences in location and/or prey or differing behavioural demands. Brünnichs guillemots Uria lomvia forage in the same location during incubation and brooding. However, during brooding, they dive deeper and spend more time submerged than during incubation (Benvenuti et al. 2002). It is thought that during brooding, the birds bring back fish to feed to their chicks while during incubation they feed on planktonic crustceans. In breeding king penguins, the interaction between both breeding stage and food availability influences foraging and diving behaviour (Charrassin et al. 1998, 1999). More detailed studies of penguins breeding at Heard Island and the Crozet Archipelago have shown that king penguins use different foraging areas during the summer and winter (Moore et al. 1999, Charrassin \& Bost 2001). In the summer, the majority of penguins 
from both locations feed at the Polar Front. Heard Island penguins swim NNE to reach this, whereas Crozet penguins travel south. In winter, both populations travel south to reach the ice edge and their foraging behaviour also changes. For the Heard Island penguins, it is suggested that they dive deeper and longer in the winter as they switch their diet from myctophid fish to squid (Moore et al. 1999). The Crozet penguins are thought to change to deeper and longer diving in the winter so that they can continue to exploit the portion of the water column below the surface mixed layer (SML). The SML is substantially deeper during winter (Charrassin \& Bost 2001), and this pattern of behaviour is also shown by subantarctic fur seals foraging around Amsterdam Island (Georges et al. 2000).

\section{Seasonal variability in diving timing and frequency}

The present study suggests that diving by macaroni penguins during winter tends to be more efficient than in summer. Surface durations were shorter and therefore the D/S ratio and DE were greater. The penguins performed fewer dives in a day and spent less of the day submerged in the winter, but spent a greater proportion of the time between the first and last dive submerged. They performed slightly fewer dives $\mathrm{h}^{-1}$ during the winter, presumably because the dives were longer. Most penguins depend on their vision to capture prey, and therefore feed during daylight hours (Wilson et al. 1993, Cannell \& Cullen 1997, Jansen et al. 1998). Indeed, light has been suggested to be the main limiting factor in the foraging behaviour of rockhopper penguins (Schiavini \& Rey 2004). King penguins are able to feed at night, but usually avoid doing so (Bost et al. 2002), only increasing their foraging intensity during the night when day length decreases during autumn and winter (Moore et al. 1999). Fig. 6 indicates high variability in the start and end times of diving during summer, and although diving start time followed sunrise relatively closely, the penguins frequently finished diving before sunset. Contrast this with the behaviour in winter when, even though their location and hence the exact sunset and sunrise times are unknown, diving start and stop times were synchronous from day to day. Table 5 indicates that during the winter there was a far stronger association between day length and mean daily dive rate and total time spent diving.

Considered together, the data suggest that macaroni penguins at South Georgia are under more pressure to dive during the winter and this pressure is compounded by the lack of daylight in which to forage, which leads to diving being more efficient. The reasons for this are unclear. Food may be scarcer at the winter foraging locations, as primary productivity drops (Foxton 1956, Clarke 1988). Penguins often have to dive more frequently (Charrassin et al. 1998, Radl \& Culik 1999) or alter time allocation during dives (Charrassin et al. 2002) to maintain their intake of prey in response to decreased prey availability. Energetic demands are bound to be greater in winter than during the brood and crèche periods, since the penguins spend the night in water and metabolic rate at night is far higher in water than it is on land (Green et al. 2002). Diving animals forage most efficiently when prey are located at a predictable depth and they can dive within their maximum duration (e.g. Parkes et al. 2002). Longer and deeper dives during winter may suggest that prey are located outside the optimal foraging depth range. It is possible that time use is less efficient during the summer because the penguins have to travel between the breeding colony and feeding areas. However, there was no significant difference in the proportion of shallow dives between brood/crèche and winter, so while the amount of time spent travelling per day may have been greater during the summer, the proportion of time devoted to it was unchanged.

Many authors have assumed that for seabirds, the chick-rearing period is the time in the annual (or biannual) cycle with the greatest energy requirements while foraging, as adults have to provision their chicks, travel between feeding grounds and breeding colonies and spend time guarding the chick(s) (e.g. Ricklefs 1983, Salamolard \& Weimerskirch 1993, Guinet et al. 1997). If this were true, then seabirds would be under most pressure to forage efficiently at this time. Instead, our data show that despite the lack of daylight, the whole population of penguins exerts a similar predation pressure on the ecosystem in the middle of winter as in the middle of summer, and the period of highest pressure is in the spring, immediately before returning to land to breed (Fig. 7). Macaroni penguins arrive back at the breeding colony weighing around $5 \mathrm{~kg}$. They then fast for up to $40 \mathrm{~d}$ during courtship and incubation (Williams \& Croxall 1991), so the peak in foraging activity may be a result of the requirement to consume more food to build up body reserves. Alternatively, this may simply be a time of low prey availability leading to an increase in foraging effort, partly because the penguins travel from their wintering areas to the breeding colony and may pass through areas of low productivity.

\section{Sex-based differences in foraging behaviour}

As might be expected, the foraging behaviour of male and female penguins was quite different. Macaroni penguins are sexually dimorphic; males are ap- 
proximately $15 \%$ larger than females (Williams 1995). Most diving variables scale with body size (Schreer \& Kovacs 1997, Walker \& Boersma 2003), so it is not surprising that male penguins can dive deeper and longer than females. This in turn influences surface duration and the number of dives per hour and per day. There was no difference in the time and proportion of time spent submerged or the D:S ratio. This suggests that male and female penguins foraged in different portions of the water column but at the same intensity and/or efficiency. This difference in dive depth may explain observed differences in foraging areas during the breeding season (Barlow \& Croxall 2002b). This in turn may account for the slight differences in DE and bottom time observed in the present study. Alternatively, differential use of the water column may allow males and females to forage at the same location at other times of year (Mori \& Boyd 2004). Despite the apparently unequal division of labour between the sexes in macaroni penguins, they appear to be subject to similar constraints during their annual cycle.

\section{Interannual variation in foraging behaviour}

The change in behaviour between phases was consistent between individuals and, although there was some variability between years in the differences between phases, there was no overall difference in foraging behaviour between years. The South Georgia marine ecosystem is highly variable between years (Murphy et al. 1998), although neither of the breeding seasons of the years of the present study was considered to be a period of abnormally low prey abundance, based on a suite of krill-predator performance indices (K. Reid pers. comm.). There was no difference in the foraging range and location of macaroni penguins during the breeding season between 2 years of low krill abundance (Barlow \& Croxall 2002b). However, aspects of chick-rearing and provisioning varied in response to years of different food availability (Barlow \& Croxall 2002a), and the timing of breeding was substantially different following a severe and prolonged winter (Williams \& Rodwell 1992). It seems probable then, that had the present study included a year of low prey abundance or climatic variation, that more interannual variation would have been observed, as is shown by Antarctic fur seals which also feed on Antarctic krill and breed at the same location (Boyd et al. 1994). The lack of interannual variability also suggests that overall, whatever causes the intra-annual variability is likely to be relatively consistent between years, and therefore relatively large in scale. Further work on the foraging location and diet of this species throughout the year is necessary to determine exactly what this cause is.

\section{CONCLUSIONS}

For the first time we have been able to record foraging behaviour in a free-ranging marine predator throughout its annual cycle. Macaroni penguins show considerable flexibility in their behaviour as they respond to differing environmental pressures throughout their annual cycle. The penguins modified their foraging behaviour as they foraged in different locations and under different daylight regimes. We were unable to determine the diet of the penguins, but this will undoubtedly interact with these parameters to create the observed patterns of behaviour. Surprisingly, the period of the year in which macaroni penguins exert most pressure on their ecosystem appears to be at the end of the winter as they prepare to return to South Georgia to breed. The maximum foraging effort observed at this time may simply be related to a lack of prey, but either way identifies the period of the annual cycle at which macaroni penguins would be most vulnerable to a food shortage or environmental change.

Acknowledgements. The authors would like to thank C. Green who assisted in the retrieval of the data loggers and the rest of the science team at Bird Island, especially J. Tanton. The authors would also like to thank the 3 anonymous referees, and Dr. C. R. White and Dr. F. C. King for helpful discussions and comments on the manuscript. This work was funded by the NERC under their Antarctic Funding Initiative (AFI) with logistical support provided by the British Antarctic Survey.

\section{LITERATURE CITED}

Barlow KE, Croxall JP (2002a) Provisioning behaviour of macaroni penguins Eudyptes chrysolophus. Ibis 144:248-258

Barlow KE, Croxall JP (2002b) Seasonal and interannual variation in foraging range and habitat of macaroni penguins Eudyptes chrysolophus at South Georgia. Mar Ecol Prog Ser 232:291-304

Barlow KE, Boyd IL, Croxall JP, Reid K, Staniland I, Brierley AS (2002) Are penguins and seals in competition for Antarctic krill at South Georgia? Mar Biol 140:205-213

Benvenuti S, Dall'Antonia L, Falk K (2002) Diving behaviour differs between incubating and brooding Brünnichs guillemots, Uria lomvia. Polar Biol 25:474-478

Bevan RM, Butler PJ, Woakes AJ, Prince PA (1995) The energy expenditure of free-ranging black-browed albatrosses. Philos Trans R Soc Lond B Biol Sci 350:119-131

Bost CA, Zorn TA, Le Maho Y, Duhamel G (2002) Feeding of diving predators and diel vertical migration of prey: king penguins' diet versus trawl sampling at Kerguelen Islands. Mar Ecol Prog Ser 227:51-61

Boyd IL, Arnould JPY, Barton T, Croxall JP (1994) Foraging behaviour of Antarctic fur seals during periods of contrasting prey abundance. J Anim Ecol 63:703-713

Boyd IL, Staniland IJ, Martin AR (2002) Distribution of foraging by female Antarctic fur seals. Mar Ecol Prog Ser 242: 285-294

Brooke M de L (2004) The food consumption of the world's seabirds. Proc R Soc 271:s246-s248 
Brown CR, Klages NTW (1987) Seasonal and annual variation in diets of macaroni (Eudyptes chrysolophus) and southern rockhopper (E. chrysocome chrysocome) penguins at subantarctic Marion Island. J Zool 212:7-28

Cannell BL, Cullen JM (1997) The foraging behaviour of little penguins (Eudyptula minor) at different light levels. Ibis 140:467-471

Charrassin JB, Bost CA (2001) Utilisation of the oceanic habitat by king penguins over the annual cycle. Mar Ecol Prog Ser 221:285-297

Charrassin JB, Bost CA, Pütz K, Lage J, Dahier T, Zorn T, Le Maho Y (1998) Foraging strategies of incubating and brooding king penguins Aptenodytes patagonicus. Oecologia 114:194-201

Charrassin JB, Bost CA, Pütz K, Lage J, Dahier T, Le Maho Y (1999) Changes in depth utilization in relation to the breeding stage: a case study with the king penguin Aptenodytes patagonicus. Mar Ornithol 27:43-47

Charrassin JB, Le Maho Y, Bost CA (2002) Seasonal changes in the diving parameters of king penguins (Aptenodytes patagonicus). Mar Biol 141:581-589

Clarke A (1988) Seasonality in the Antarctic marine environment. Comp Biochem Physiol 90:461-473

Croxall JP (1984) Seabirds. In: Laws RM (ed) Antarctic ecology. Academic Press, London, p 533-619

Croxall JP (ed) (1987) Seabirds: feeding ecology and role in marine ecosystems. Cambridge University Press, Cambridge

Croxall JP (1995) Remote-recording of foraging patterns in seabirds and seals for studies of predator-prey interactions in marine systems. In: Skjoldal HR, Hopkins C, Erikstad KE, Leinaas HP (eds) The ecology of fjords and coastal waters. Elsevier Science, Amsterdam, p 429-442

Croxall JP, Lishman GS (1987) The food and feeding ecology of penguins. In: Croxall JP (ed) Seabirds: feeding ecology and role in marine ecosystems. Cambridge University Press, Cambridge, p 101-133

Croxall JP, Briggs DR, Kato A, Naito Y, Watanuki Y, Williams TD (1993) Diving pattern and performance in the macaroni penguin Eudyptes chrysolophus. J Zool 230:31-47

Croxall JP, Prince PA, Reid K (1997) Dietary segregation of krill-eating South Georgian seabirds. J Zool 242:531-536

Croxall JP, Silk JRD, Phillips RA, Afanasyev V, Briggs DR (2004) Global circumnavigations: tracking year-round ranges of non-breeding albatrosses. Science 307:249-250

Davis RW, Croxall JP, O'Connell MJ (1989) The reproductive energetics of gentoo (Pygoscelis papua) and macaroni (Eudyptes chrysolophus) penguins at South Georgia. J Anim Ecol 58:59-74

Foxton P (1956) The distribution of standing crop of zooplankton in the Southern Ocean. Discov Rep 28:191-236

Georges JY, Tremblay Y, Guinet C (2000) Seasonal diving behaviour in lactating subantarctic fur seals on Amsterdam Island. Polar Biol 23:59-69

Godlewska M (1996) Vertical migrations of krill (Euphausia superba Dana). Pol Arch Hydrobiol 43:9-63

Green JA, Butler PJ, Woakes AJ, Boyd IL (2002) Energy requirements of female macaroni penguins breeding at South Georgia. Funct Ecol 16:671-681

Green JA, Butler PJ, Woakes AJ, Boyd IL (2003) Energetics of diving in macaroni penguins. J Exp Biol 206:43-57

Green JA, Tanton JL, Woakes AJ, Boyd IL, Butler PJ (2004) Effects of long-term implanted data loggers on macaroni penguins. J Avian Biol 35:370-376

Green K, Williams R, Green MG (1998) Foraging ecology and diving behaviour of macaroni penguins Eudyptes chrysolophus at Heard Island. Mar Ornithol 26:27-34
Guinet C, Koudil M, Bost CA, Durbec JP, Georges JY, Mouchot MC, Jouventin P (1997) Foraging behaviour of satellite-tracked king penguins in relation to sea-surface temperatures obtained by satellite telemetry at Crozet Archipelago, a study during three austral summers. Mar Ecol Prog Ser 150:11-20

Hull CL (1997) The effect of carrying devices on breeding royal penguins. Condor 99:530-534

Hull CL (1999) Comparison of the diets of breeding royal (Eudyptes schlegi) and rockhopper (Eudyptes chrysocome) penguins on Macquarie Island over three years. J Zool 247:507-529

Hull CL (2000) Comparative diving behaviour and segregation of the marine habitat by breeding royal penguins, Eudyptes schlegi, and eastern rockhopper penguins, Eudyptes chrysocome filholi, at Macquarie Island. Can J Zool 78:333-345

Hull CL, Hindell MA, Michael K (1997) Foraging zones of royal penguins during the breeding season, and their association with oceanographic features. Mar Ecol Prog Ser 153:217-228

Jansen JK, Boveng PL, Bengston JL (1998) Foraging modes of chinstrap penguins: contrasts between day and night. Mar Ecol Prog Ser 165:161-172

Kato A, Watanuki Y, Naito Y (2003) Annual and seasonal changes in foraging site and diving behaviour in Adélie penguins. Polar Biol 26:389-395

Lea MA, Hindell MA, Guinet C, Goldsworthy S (2002) Variability in the diving activity of Antarctic fur seals, Arctocephalus gazella, at Îles Kerguelen. Polar Biol 25: 269-279

Moore GJ, Wienecke B, Robertson G (1999) Seasonal change in foraging areas and dive depths of breeding king penguins at Heard Island. Polar Biol 21:376-384

Mori Y, Boyd IL (2004) Segregation of foraging between two sympatric penguin species: does rate maximisation make the difference? Mar Ecol Prog Ser 275:241-249

Murphy EJ, Watkins JL, Reid K, Trathan PN and 6 others (1998) Interannual variability of the South Georgia marine ecosystem: biological and physical sources of variation in the abundance of krill. Fish Oceanogr 7:381-390

Parkes R, Halsey LG, Woakes AJ, Holder RL, Butler PJ (2002) Oxygen uptake during post dive recover in a diving bird Aythya fuligula: implications for optimal foraging models. J Exp Biol 205:3945-3954

Phillips RA, Xavier JC, Croxall JP (2003) Effects of satellite transmitters on albatrosses and petrels. Auk 120: 1082-1090

Phillips RA, Silk JRD, Phalan B, Catry P, Croxall JP (2004) Seasonal sexual segregation in two Thalassarche albatross species: competitive exclusion, reproductive role specialization or foraging niche divergence? Proc R Soc 271:1283-1291

Radl A, Culik BM (1999) Foraging behaviour and reproductive success in Magellanic penguins (Speniscus magellanicus): a comparative study of two colonies in southern Chile. Mar Biol 133:381-393

Ricklefs RE (1983) Some considerations on the reproductive energetics of pelagic seabirds. Stud Avian Biol 8:84-94

Rodary D, Wienecke BC, Bost CA (2000) Diving behaviour of Adélie penguins (Pygoscelis adeliae) at Dumont D'Urville, Antarctica: nocturnal patterns of diving and rapid adaptations to changes in sea-ice condition. Polar Biol 23: $113-120$

Ropert-Coudert Y, Kato A, Baudat J, Bost CA, Le Maho Y, Naito Y (2001) Feeding strategies of free-ranging Adélie 
penguins Pygoscelis adeliae analysed by multiple data recording. Polar Biol 24:460-466

Ropert-Coudert Y, Kato A, Bost CA, Rodary D, Sato K, Le Maho Y, Naito Y (2002) Do Adélie penguins modify their foraging behaviour in pursuit of different prey? Mar Biol 140:647-652

Salamolard M, Weimerskirch H (1993) Relationship between foraging effort and energy requirement throughout the breeding season in the wandering albatross. Funct Ecol 7: 643-652

Schiavini A, Rey AR (2004) Long days, long trips: foraging ecology of female rockhopper penguins Eudyptes chrysocome chrysocome at Tierra del Fuego. Mar Ecol Prog Ser 275:251-262

Schreer JF, Kovacs KM (1997) Allometry of diving capacity in air-breathing vertebrates. Can J Zool 75:339-358

Stephenson R, Butler PJ, Woakes AJ (1986) Diving behaviour and heart rate in tufted ducks Aythya fuligula. J Exp Biol 126:341-359

Tremblay Y, Cherel Y (2000) Benthic and pelagic dives: a new foraging behaviour in rockhopper penguins. Mar Ecol Prog Ser 204:257-267

Tremblay Y, Cherel Y (2003) Geographic variation in the foraging behaviour, diet and chick growth of rockhopper penguins. Mar Ecol Prog Ser 251:279-297

Walker BG, Boersma PD (2003) Diving behaviour of Magellanic penguins (Speniscus magellanicus) at Punta Tombo, Argentina. Can J Zool 81:1471-1483

Weimerskirch H, Wilson RP (2000) Oceanic respite for wandering albatross. Nature 406:955-956

Editorial responsibility: Otto Kinne (Editor-in-Chief), Oldendorf/Luhe, Germany
Williams TD (1995) The penguins. Oxford University Press, Oxford

Williams TD, Croxall JP (1991) Annual variation in breeding biology of macaroni penguins, Eudyptes chrysolophus, at Bird Island, South Georgia. J Zool 223:189-202

Williams TD, Rodwell S (1992) Annual variation in return rate, mate and nest-site fidelity in breeding gentoo and macaroni penguins. Condor 94:636-645

Wilson RP, Pütz K, Bost CA, Culik BM, Bannasch R, Reins T, Adelung D (1993) Diel dive depth in penguins in relation to diel vertical migration of prey: whose dinner by candlelight? Mar Ecol Prog Ser 94:101-104

Wilson RP, Steinfurth A, Ropert-Coudert Y, Kato A, Kurita M (2002) Lip-reading in remote subjects: an attempt to quantify and separate ingestion, breathing and vocalisation in free-living animals using penguins as a model. Mar Biol 140:17-27

Woehler EJ (1993) The distribution and abundance of Antarctic and subantarctic penguins. Scientific Committee of Antarctic Reseach (SCAR) Bird Biology Sub-Committee, Cambridge

Woehler EJ, Croxall JP (1997) The status and trends of Antarctic and subantarctic seabirds. Mar Ornithol 25:43-66

Ydenberg RC, Clark CW (1989) Aerobiosis and anaerobiosis during diving by western grebes: an optimal foraging approach. J Theor Biol 139:437-449

Yoda K, Sato K, Niizuma Y, Kurita M, Bost CA, Le Maho Y, Naito Y (1999) Precise monitoring of porpoising behaviour of Adélie penguins determined using acceleration data loggers. J Exp Biol 202:3121-3126

Submitted: November 22, 2004; Accepted: March 12, 2005

Proofs received from author(s): June 28, 2005 